\title{
RESEARCH PAPER \\ SORPTION OF INORGANIC MERCURY ON SOILS FROM ANKOBRA BASIN IN THE SOUTH - WESTERN PART OF GHANA
}

\author{
D. Azanu and R.B. Voegborlo* \\ Department of Chemistry, KNUST, Kumasi \\ *Corresponding author: raybrightv@yahoo.com; rbvoegborlo.sci@knust.edu.gh
}

\begin{abstract}
Understanding the adsorption of mercury on soil from aqueous solution is necessary for tracing the fate of mercury in the environment. This study was undertaken to predict the fate of mercury emitted from artisanal gold mining activities within the Ankobra basin. Total mercury (THg) concentrations were determined in soils close to River Ankobra and its major tributaries in the south-western part of Ghana by Cold Vapour Atomic Absorption Spectrophotometry. THg content of the soils ranged from $0.051 \mu^{-1}$ to $0.366 \mu^{-1}$ with an average of $0.15 \mathrm{\mu gg}^{-1}$ which was below the level $\left(200 \mu^{-1}\right)$ set by US EPA. THg correlated positively $(r=0.57)$ with the organic matter content of the soil. Sorption of $\mathrm{Hg}$ (II) onto the soils had an L - type isotherm and the distribution coefficient $\left(K_{d}\right)$ ranged from $41.4 \mu^{-1}$ to $182.2 \mu^{-1} g^{-1}$. The Freundlich model showed a better fit followed by Langmuir model and linear. The superiority of Freundlich model to the other models could be attributed to the heterogeneous surface energies and exponential distribution of active sites which are characteristics of such soils. All the soils had adsorption intensity (n) lower than one, indicating the soils could be good sorbent for $\mathrm{Hg}$ (II). This suggests that $\mathrm{Hg}$ fate and availability in soil for runoff and leaching could be low for soils with such characteristics.
\end{abstract}

Keywords: Mercury, Isotherms, Ankobra Basin, soil

\section{INTRODUCTION}

Human activities such as mining and associated smelting, burning of fossil fuels, and industrial uses of mercury $(\mathrm{Hg})$ in paints, batteries, medicine, and dentistry have been increasing the global reservoir of atmospheric mercury since the beginning of the industrialized period (Fitzgerald et al., 1998). This Hg is widely distributed via atmospheric processes, and deposi- tion from the atmosphere into terrestrial and aquatic systems even in remote areas has led to the recognition of $\mathrm{Hg}$ as a global pollutant (Jackson, 1997; Fitzgerald et al., 1998). Point sources are important in delivering $\mathrm{Hg}$ to aquatic systems, but atmospheric $\mathrm{Hg}$ deposition, either directly to the aquatic system or indirectly via deposition to terrestrial watersheds and its subsequent transport, is also 
significant (Fitzgerald et al., 1998; Schroeder and Munthe, 1998).

High concentrations of mercury have been found in sediments and fish in the vicinity of small-scale mining activities using amalgamation as their main technique. Mercury contamination of the environment from gold mining using $\mathrm{Hg}$ in the amalgamation step has already been postulated as one of the worst environmental problems (Melamed and Villas Boas, 1998). It has been estimated that, 5 tonnes of mercury is released from small-scale mining operations in Ghana each year (Hilson, 2001). Understanding the adsorption of mercury on soil from aqueous solution is necessary for tracing the fate of mercury in the biological environment and the impact of anthropogenic mercury emissions on the environment. Sorption or exchange has been described by either instantaneous equilibrium or a kinetic reaction where concentrations in solution and sorbed phases vary with time. The adsorption of $\mathrm{Hg}$ by soils can be influenced by a number of experimental as well as soil factors. Soil organic matter is known to play a role in $\mathrm{Hg}$ adsorption, although its quantitative contribution is not clearly understood. It has been reported that soils, rich in organic matter, adsorbed significantly higher amounts of $\mathrm{Hg}$ as compared to other soils which contained relatively smaller quantities of organic matter (Trost and Bisque, 1972; Estes et al., 1973; Fang, 1978; Landa, 1978; Lag and Steinnes, 1978). Adsorption of $\mathrm{Hg}$ by organic matter is thought to take place via functional groups such as $\mathrm{COOH}$ and phenolic-OH, which are major constituents of organic matter (Lamar, 1968). Given the high levels of mercury in the soils of the artisanal gold mining areas and the health risks associated with the element, an insight into the sorption of mercury in this matrix is extremely important. Data on the sorption of inorganic $\mathrm{Hg}$ (II) on soils are available in literature (Schnoor, 1996; Yin et al., 1996; Schlüter and Gäth, 1997; Yin et al., 1997a; 1997b; Grigal, 2003) but so far none deals with Ghanaian soils. It is therefore important to determine sorption model for some Ghanaian soils within the mining environment.

The main river in the Ankobra Basin is River Ankobra which takes its source around Bibiani and passes through Bogoso and Prestea all of which are mining towns in Ghana. In addition, its major tributaries: river Mansi, river Bonsa and river Fure all pass through mining communities before joining the main Ankobra, which finally enters the Gulf of Guinea at Axim (Fig. $1)$. There is therefore the possibility of mercury contamination of the environment as a result of artisanal gold mining activities close to the rivers but, the leachability of the mercury contaminant depends on the chemistry of the soil. This study reports the relationship between total mercury and some soil characteristics, the adsorption isotherms for some soils from the Ankobra Basin and the isotherm that best fits the experimental data.

\section{MATERIALS AND METHODS}

All glassware used for dilution, storage and experiments were cleaned with detergent solution, rinsed with distilled water and soaked in $10 \%$ (v/v) $\mathrm{HNO}_{3}$ overnight. They were rinsed with distilled water followed by $0.5 \%(\mathrm{w} / \mathrm{v})$ $\mathrm{KMnO}_{4}$ and finally rinsed with distilled water and dried before use. All reagents used were of analytical grade (BDH Chemicals Ltd, Poole, England) unless otherwise stated. Doubled distilled water was used for the preparation of all solutions. Mercury stock standard solution (1000 $\mathrm{mg} \mathrm{L} \mathrm{L}^{-1}$ ) was prepared by dissolving $0.0677 \mathrm{~g}$ of $\mathrm{HgCl}_{2}$ in the acid mixture of $\mathrm{HNO}_{3}$ : $\mathrm{H}_{2} \mathrm{SO}_{4}: \mathrm{HClO}_{4}(1: 5: 1)$ in a $50 \mathrm{ml}$ digestion flask with heating on a hot plate at a temperature of $200{ }^{\circ} \mathrm{C}$ for thirty (30) minutes. The solution was then diluted to $50 \mathrm{ml}$ with water. Blank solutions were also prepared alongside. The working standard solutions were freshly prepared by diluting an appropriate aliquot of the stock solution through intermediate solutions using blank solution. Stannous Chloride solution $(10 \% \mathrm{w} / \mathrm{v})$ was prepared by dissolving $10 \mathrm{~g}$ of $\mathrm{SnCl}_{2} \cdot 2 \mathrm{H}_{2} \mathrm{O}$ in $100 \mathrm{ml}$ of $1 \mathrm{M} \mathrm{HCl}$ solution. The solution was aerated with nitrogen gas 


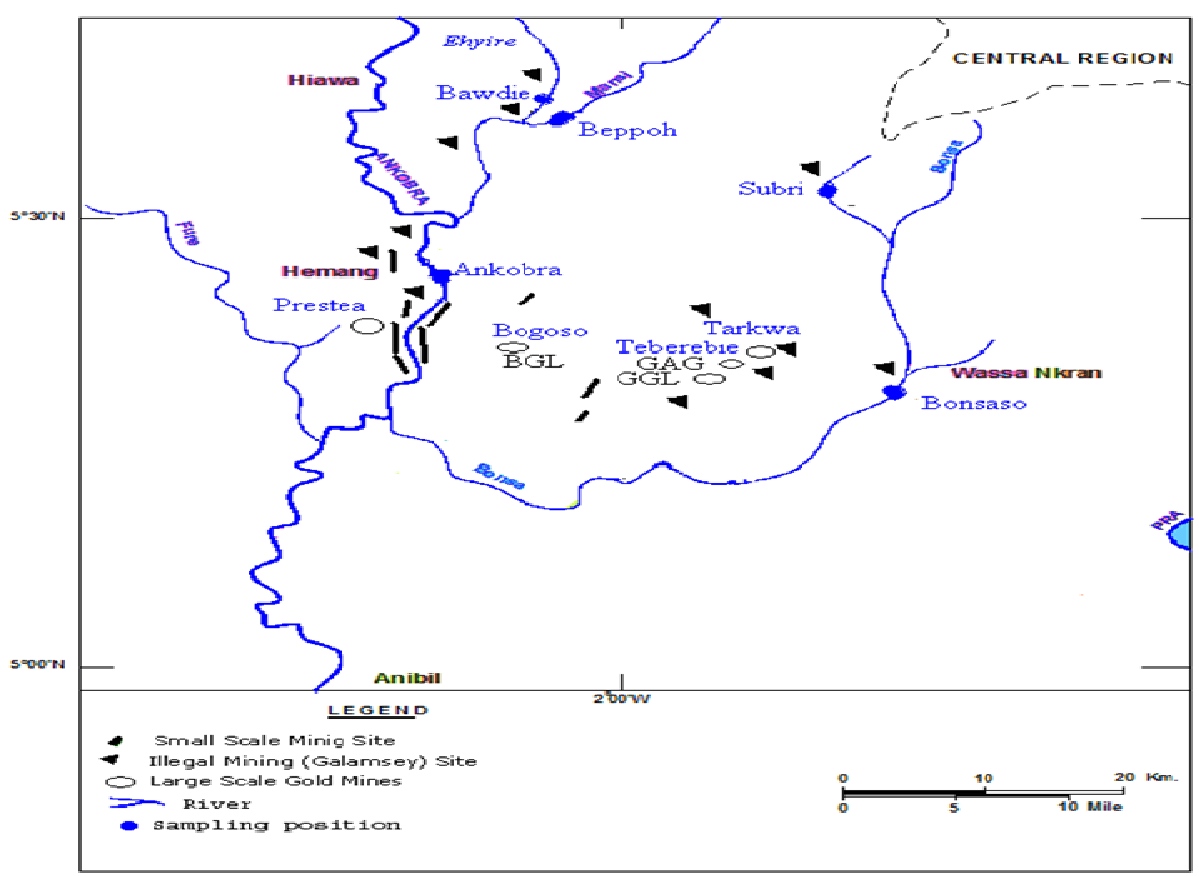

Fig. 1 Map showing the sampling locations. (Modified from Kortatsi, 2004)

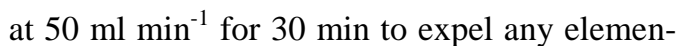
tal mercury from it. $\mathrm{Hg}$ solutions for sorption studies were prepared from $1000 \mathrm{mg} \mathrm{l}^{-1}$ mercury nitrate stock dilution (BDH Chemicals Ltd, Poole, England).

Seven (7) surface soil samples $(0-10 \mathrm{~cm})$ were collected close to the main river Ankobra and its major tributaries at Ankobra (AA) Bonsa (BB), Subri (SS), Beppoh (BM), Bawdie (BE), Teberebie (TB) and Efuanta (EB) using a shovel. Samples were randomly collected from both sides of the river, air dried and passed through a $2 \mathrm{~mm}$ sieve. Soil $\mathrm{pH}$ was determined using the ratio of 1: $2.5(\mathrm{w} / \mathrm{v})$ soil: water (McLean, 1982). Organic matter was determined by dichromate oxidation method (Nelson and Sommers, 1975). Particle size distribution was determined using hydrometer method (Gee and Bauder, 1986). To determine the period that will be sufficient to attain equilibrium, one
(1) gram of soil sample (BE) was accurately weighed in triplicate into a $15 \mathrm{ml}$ centrifuge tube and $10 \mathrm{ml}$ of $80 \mu \mathrm{g} \mathrm{l}^{-1} \mathrm{Hg}$ (II) solution prepared from $\mathrm{HgNO}_{3}$ in $1 \% \mathrm{HNO}_{3}$ was added. The tubes containing the suspensions were then shaken at different times over twenty-four hours at a speed of $1400 \mathrm{rpm}$. Suspensions were taken after $30 \mathrm{~min}, 1 \mathrm{hr}, 1.5 \mathrm{hr}, 2 \mathrm{hr}, 6 \mathrm{hr}$, $10 \mathrm{hr}, 14 \mathrm{hr}, 18 \mathrm{hrs}$ and $22 \mathrm{hrs}$. The suspension was centrifuged at a speed of $4000 \mathrm{rpm}$ for 15 minutes. The supernatant was analysed for total mercury. Amount sorbed was calculated from the difference between the initial concentration of $\mathrm{Hg}$ (II) solution and the equilibrium concentration. Isotherm studies were performed using batch method with different $\mathrm{Hg}$ (II) concentrations in 1:10 soil: $\mathrm{Hg}$ (II) solution as used by Khalid et al. (1977). Soil suspensions were shaken for $90 \mathrm{~min}$ at $1400 \mathrm{rpm}$ and at room temperature. At the end of the shaking period, samples were centrifuged and mercury deter- 


\section{Azanu and Voegborlo}

mined in the supernatant.

\section{Mercury Determination}

Automatic Mercury Analyzer Model HG-5000 (Sanso Seisakusho Co., Ltd, Japan), equipped with mercury lamp operated at a wavelength of $253.7 \mathrm{~nm}$ was used for total mercury and $\mathrm{Hg}$ (II) concentration in the supernatant was determined after an open flask digestion procedure (Akagi and Nishimura, 1991). The initial mercury concentrations added were also determined. Amount sorbed was calculated from the difference between the initial concentration of $\mathrm{Hg}$ in solution and the equilibrium concentration in the supernatant.

\section{RESULTS AND DISCUSSION \\ Total Mercury in the Soil Samples}

Total mercury (THg) concentrations were determined in surface soils from the Ankobra basin in the south- western part of Ghana. In all, a total of seven soil samples were collected close to the main river Ankobra and its major tributaries at Ankobra (AA) Bonsa (BB), Subri (SS), Beppoh (BM), Bawdie (BE), Teberebie (TB) and Efuanta (EB) and analyzed for total mercury. Summary of results of soil total mercury concentration $(\mathrm{THg})$, soil $\mathrm{pH}$, soil organic matter $(\mathrm{OM})$ and particle size distribution are presented in Table 1. Each THg value is the mean of three replicate samples \pm standard deviation. The $\mathrm{THg}$ of the soils ranged from $0.051 \mu \mathrm{g} \mathrm{g}^{-1}$ to $0.366 \mu \mathrm{g} \mathrm{g}^{-1}$ with an average of $0.15 \mu \mathrm{g} \mathrm{g}^{-1}$. The total $\mathrm{Hg}$ content measured in this study was below the level set by US EPA $\left(200 \mu \mathrm{g} \mathrm{g}^{-1}\right)$. Considering the sampling sites, soil from Efuanta (EB) had the highest mean $\mathrm{THg}$ with $0.366 \mu \mathrm{g} \mathrm{g}^{-1}$ compared to the others. Samples from Ankobra (AA) had the second highest mean THg $\left(0.195 \mu \mathrm{g} \mathrm{g}^{-1}\right)$ which is about half that of samples from Efuanta (EB). Soil samples from Bawdie (BM) had the lowest THg content $\left(0.051 \mu \mathrm{gg}^{-1}\right)$.

The THg data from this study was subjected to Pearson correlation analysis to determine the relationship between mercury concentrations in the soil samples and some soil characteristics.
The results are presented in Table 2 in the form of a matrix of correlation coefficients.

\section{THg and Some Soil Characteristics}

Soil organic matter is known to play a role in $\mathrm{Hg}$ adsorption, although its quantitative contribution is not clearly understood (Semu and Singh, 1987). The THg correlated positively (r $=0.57$ ) with the OM in the soil. This indicates increasing $\mathrm{Hg}$ concentration with increasing organic matter content. Lag and Steinnes (1978) also found a positive correlation between total $\mathrm{Hg}$ and organic matter content of forest soils.

Biester et al. (2002) found that high clay content in soils inhibited the leachability of $\mathrm{Hg}$ and Parkpian et al. (2001) also reported that the high content of clay in sediments made $\mathrm{Hg}$ less bioavailable. In this study, it was found that the percent soil clay had slight negative correlation $(\mathrm{r}=-0.47, \mathrm{p}<0.05)$ with $\mathrm{THg}$ concentration. This could suggest that soil with high content of clay would have low level of $\mathrm{Hg}$.

The $\mathrm{pH}$ of the soils in this study had no significant correlation $(r=-0.19, p<0.05)$ with the THg concentration. This could suggest that soil $\mathrm{pH}$ has no direct effect on $\mathrm{THg}$ concentration in soil. Despite several investigations on soil $\mathrm{pH}$ values as one of the two most important factors which may significantly influence the $\mathrm{Hg}$ geochemistry under various conditions including soil transport, transformation processes, and also exchange/release flux via the interface no significant correlation has been established between $\mathrm{pH}$ values and $\mathrm{Hg}$ concentration in soil (Semu and Singh, 1987) which this study has also corroborated.

\section{Qualitative Description of Sorption Iso- therms}

In sorption studies, it is very important to equilibrate the adsorbent and adsorptive long enough to ensure that a steady state is reached. In this study, the period required to attain equilibrium was determined using soil sample from Efuanta (EB) because it has the highest organic 


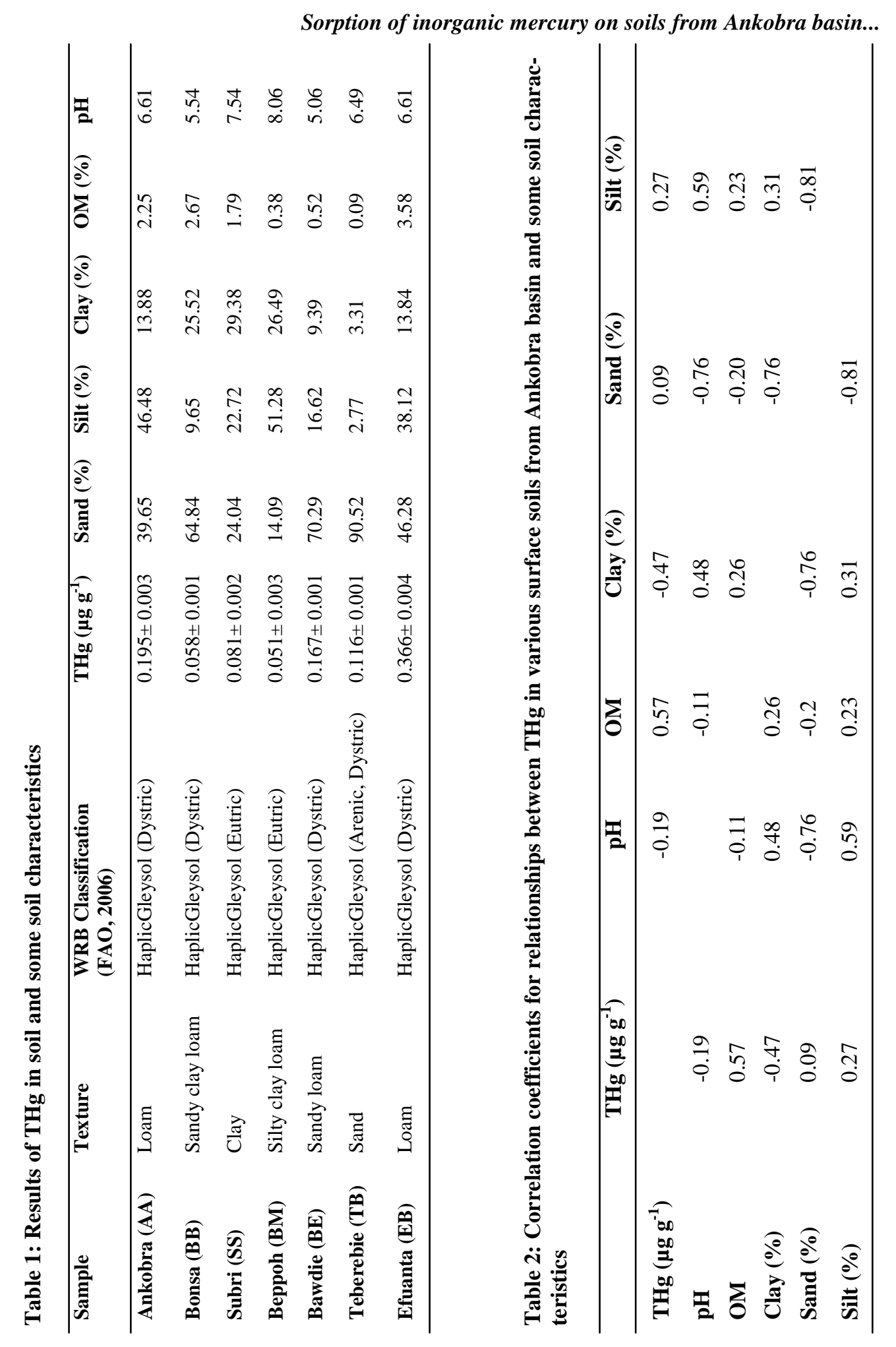

Journal of Science and Technology @ KNUST December 2013 


\section{Azanu and Voegborlo}

matter. The sorption of $\mathrm{Hg}$ in the soil exhibited an initial rapid sorption within 1 hour; followed by a slight decrease in amount sorbed and then a steady rate of sorption over the rest of the 24 hour period. This experiment indicated that a period of $90 \mathrm{~min}$ is about sufficient to attain equilibrium for all of the $\mathrm{Hg}$ (II) solutions and this was used throughout this study. This equilibration period obtained is in agreement with 90 minutes equilibration period obtained by $\mathrm{Mi}$ retzky et al. (2005). The amount of $\mathrm{Hg}$ (II) sorbed against time of shaking is presented in Fig. 2.

Giles et al. (1974) classified sorption isotherms based on their initial slopes and curvatures. They distinguished between high affinity $(\mathrm{H})$, Langmuir (L), constant partition (C), and sigmoidal -shaped (S) isotherm classes. All the soils in this study had an L - type isotherm according to the classification of Giles et al.
(1974). The L- shaped isotherm is characterized by a decreasing slope as concentration increases because vacant adsorption sites decrease as the adsorbent becomes covered. This provides a concave curve. Such adsorption behaviour could be explained by the high affinity of the adsorbent for the adsorptive at low concentrations, which then decreases as concentration increases. It suggests a progressive saturation of the solid, but the curve does not reach any plateau (the soil does not show clearly a limited sorption capacity). This means that the theoretical monolayer has not been completed and the monolayer sorption could be as a result of different retention mechanisms, new sites, or the development of a fresh surface where retention can take place (Harter, 1991). The graph showing the amount sorbed versus the equilibrium concentration for all the soils is presented in Fig. 3.

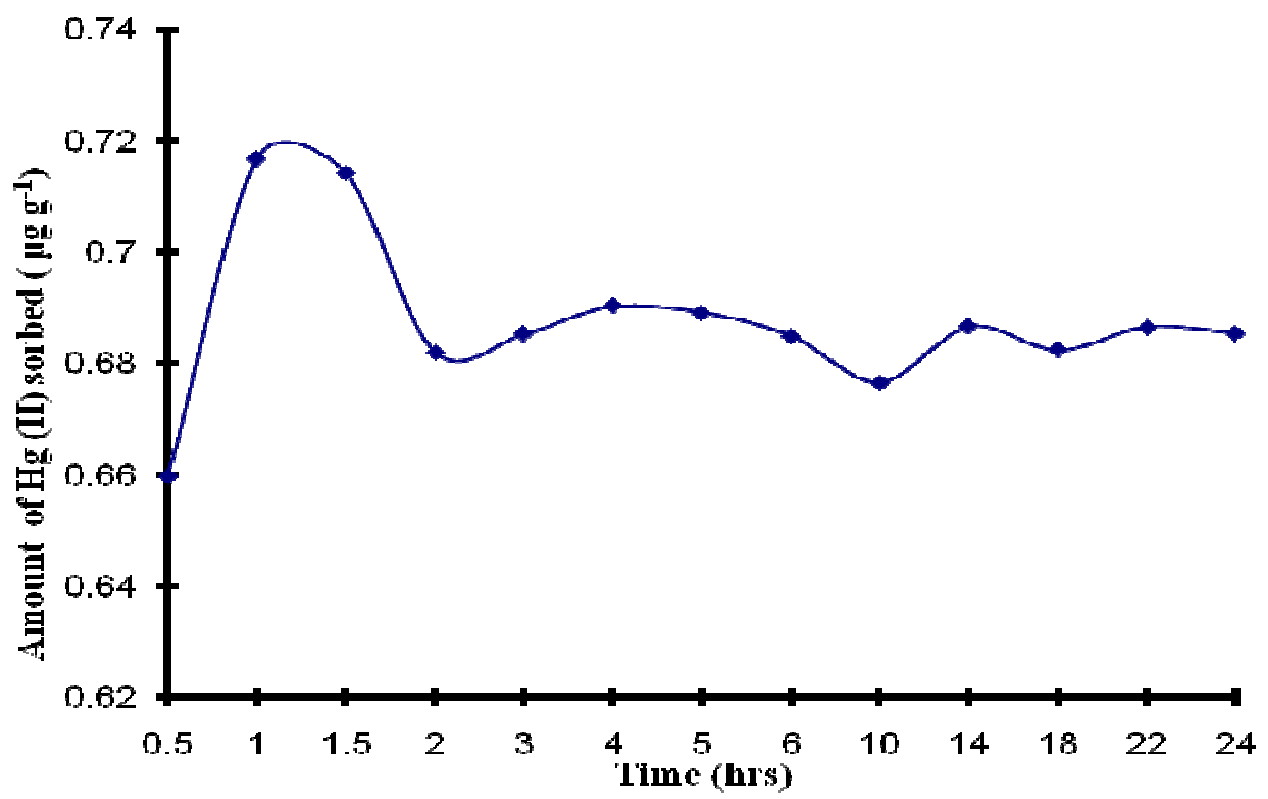

Fig. 2: Amount of $\mathrm{Hg}$ sorbed against time of shaking 


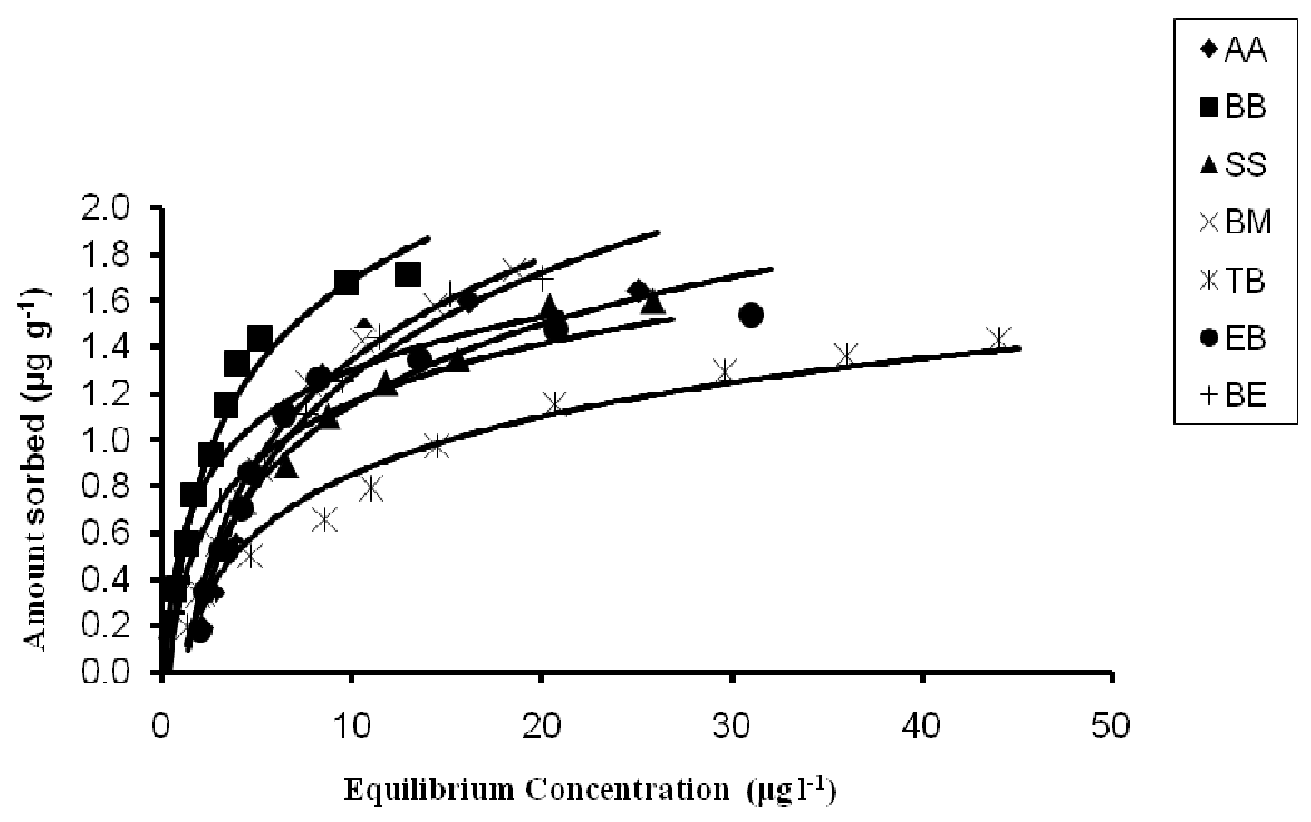

Fig. 3: Amount sorbed against equilibrium concentration

In this study, there was a sharp increase in the rate of sorption with increase in initial concentration of $\mathrm{Hg}$ (II) for the various soil samples. For instance, for soil from Bonsa (BB), increase in equilibrium concentration led to sharp increase in amount sorbed to a point (amount sorbed $=1.437 \mu \mathrm{g} \mathrm{g}^{-1}$ ) where it further increased slightly. For soil sample from Ankobra (AA) increase in initial concentration led to increase in amount sorbed to a maximum point (1.600) where further increase in concentration of $\mathrm{Hg}$ (II) resulted in no significant effect on amount sorbed. This was observed for all the soils, except for soil sample from Teberebie (TB) where increase in concentration led to a slight increase in the amount sorbed.

Generally, increase in initial concentration of the $\mathrm{Hg}$ (II) resulted in an increase in the amount sorbed for the soil samples. However the extent of increase varies with regards to the initial concentrations. For instance, increase in con-

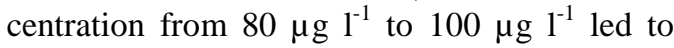
increase in amount sorbed for BE by 0.32 , for $\mathrm{BB}$ the increase was higher (0.39). The increase in concentration resulting in a decrease in the amount of solute sorbed suggests a progressive saturation of the soil surface.

\section{Quantitative Description of Sorption Iso- therms}

Traditionally, the sorption of ions by soils has been quantitatively described by parameters obtained either directly from isotherms or by least square analysis with Linear, Langmuir and Freundlich isotherms.

The data from this study was subjected to Linear, Langmuir and Freundlich models to determine sorption parameters and identify the model which gives the best fit. Linear isotherm was used to show relationship between the con- 
centration of $\mathrm{Hg}$ (II) remaining in solution and amount sorbed on the soil. The linear sorption isotherm assumes that the sorbed concentration is directly proportional to the dissolved concentration.

The linear equation is described by:

$\mathrm{C}_{\mathrm{s}}=\mathrm{K}_{\mathrm{d}} \mathrm{C}_{\mathrm{e}}$

Where Cs is the amount sorbed per unit weight of soil $\left(\mu \mathrm{g} \mathrm{g}^{-1}\right) ; \mathrm{K}_{\mathrm{d}}$ is the linear distribution coefficient $\left(\mathrm{L} \mathrm{kg}^{-1}\right)$; and $\mathrm{C}_{\mathrm{e}}$ is the equilibrium concentration $\left(\mu \mathrm{g}^{-1}\right)$.

The plot showing the Linear model for all the soils shows that soil from Bonsa (BB) had the highest amount of $\mathrm{Hg}$ sorbed at the various concentrations followed by Beppoh (BM) and soil from Teberebie (TB) had the lowest amount of $\mathrm{Hg}$ sorbed. The plot showing the linear model for all the soils is presented in Fig.
4 and Table 3 presents the linear distribution coefficients and parameters for all the soils deduced from the application of the linear model.

The distribution coefficient $\left(\mathrm{K}_{\mathrm{d}}\right)$, which is the slope of a simple linear model, is often used to characterize the mobility of trace metals in aquatic environment: Low $\mathrm{K}_{\mathrm{d}}$ values imply that most of the metal remains in solution, and high $\mathrm{K}_{\mathrm{d}}$ values indicate that the soil has great affinity for the metal (Anderson and Christensen, 1988). In this study distribution coefficient $\left(\mathrm{K}_{\mathrm{d}}\right)$ ranged from $41.4 \mu \mathrm{g} \mathrm{g}^{-1}$ (TB) to $182.2 \mu \mathrm{g} \mathrm{g}^{-1}$ (BB) which is presented in Table 3. Although, soil from Efuanta (EB) had the highest $\mathrm{THg}$ and $\mathrm{OM}$, it did not have the highest distribution coefficient $\left(\mathrm{K}_{\mathrm{d}}=41.4 \mathrm{~L} \mathrm{~kg}^{-1}\right)$. This could mean that soils with high $\mathrm{OM}$ do not necessarily have high distribution coefficients, because distribution coefficient depends on other factors. In this

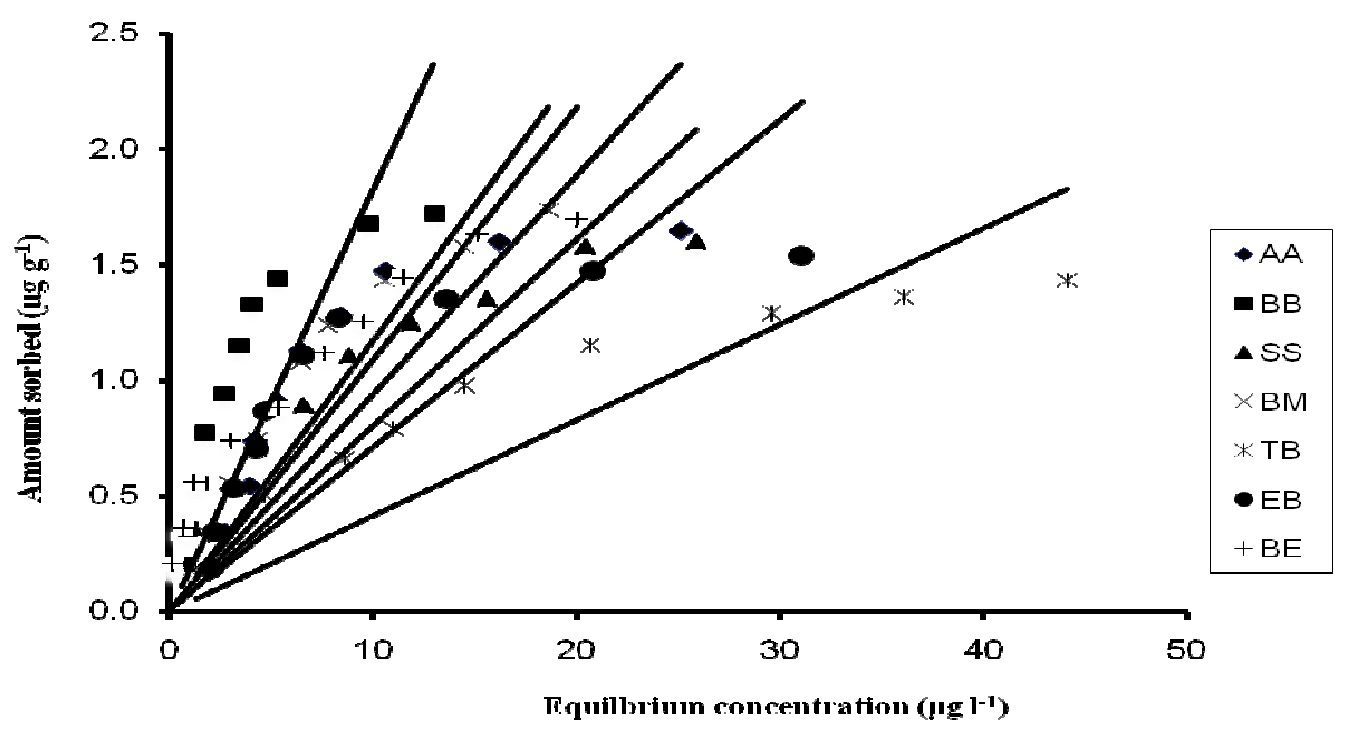

Fig. 4: Linear model for Ankobra basin soils 
Table 3: Parameters for the Linear equation

\begin{tabular}{llll}
\hline Sample & Equation & $\mathbf{K}_{\mathbf{d}}\left(\mathbf{L} \mathbf{k g}^{-1}\right)$ & $\mathbf{R}^{\mathbf{2}}$ \\
\hline Ankobra (AA) & $\mathrm{y}=0.0943 \mathrm{x}$ & 94.3 & 0.36 \\
Bonsa (BB) & $\mathrm{y}=0.1822 \mathrm{x}$ & 182.2 & 0.28 \\
Subri (SS) & $\mathrm{y}=0.0805 \mathrm{x}$ & 80.5 & 0.57 \\
Beppoh (BM) & $\mathrm{y}=0.1172 \mathrm{x}$ & 117.2 & 0.74 \\
Bawdie (BE) & $\mathrm{y}=0.1089 \mathrm{x}$ & 108.9 & 0.62 \\
Teberebie (TB) & $\mathrm{y}=0.071 \mathrm{x}$ & 71.0 & 0.03 \\
Efuanta (EB) & $\mathrm{y}=0.0414 \mathrm{x}$ & 41.4 & 0.55 \\
\hline
\end{tabular}

study, it was observed that soils with relatively high \% clay and relatively low $\mathrm{THg}$ had higher distribution coefficients. These include soil from Bonsa (BB) with $\mathrm{K}_{\mathrm{d}}$ value of $182.2 \mathrm{~L} \mathrm{~kg}^{-1}$ $\left(\%\right.$ clay $\left.=25.52, \mathrm{THg}=0.058 \mu \mathrm{g} \mathrm{g}^{-1}\right)$ and soil from Bawdie (BM) which had $\mathrm{K}_{\mathrm{d}}$ value of $108.9\left(\%\right.$ clay $\left.=26.49, \mathrm{THg}=0.051 \mu \mathrm{g} \mathrm{g}^{-1}\right)$. The ratio of organic to mineral matter in particular affects both $\mathrm{K}_{\mathrm{d}}$ and particulate $\mathrm{THg}$ concentration, with stronger binding associated with higher organic content (Mason and Sullivan, 1998). With regards to soil characteristics, a strong positive correlation was found to exist between the linear distribution coefficient and $\%$ clay $(\mathrm{r}=0.65, \mathrm{p}<0.05)$, and a slight positive correlation between distribution coefficient and organic matter $(\mathrm{r}=0.35, \mathrm{p}<0.05)$. A weak negative correlation was found between the distribution coefficient and soil $\mathrm{pH}(\mathrm{r}=-0.17, \mathrm{p}$ $<0.05)$ Table 4. Ranking the soils by their $\mathrm{K}_{\mathrm{d}}$ 's: Bonsa $(\mathrm{BB})>$ Beppoh $(\mathrm{BM})>$ Bawdie (BE) >Ankobra (AA) >Subri (SS) >Teberebie (TB) >Efuanta (EB). This could suggest that soil with similar soil characteristics like Bonsa (BB) would sorb $\mathrm{Hg}$ (II) better than the others and hence could help minimize leaching of $\mathrm{Hg}$ into the aquatic environment.

Langmuir's isotherm model suggests that sorption occurs on homogeneous surface by monolayer sorption without interaction between sorbed ions. The linear form of Langmuir iso- therm equation is represented by the following equation:

$$
\mathrm{Q}_{\mathrm{e}} / \mathrm{C}_{\mathrm{e}}=\mathrm{bK}-\mathrm{KQ}_{\mathrm{e}}
$$

where $\mathrm{C}_{\mathrm{e}}$ is the equilibrium concentration $\left(\mu \mathrm{g} \mathrm{l}^{-}\right.$ $\left.{ }^{1}\right), \mathrm{Q}_{\mathrm{e}}$ is the amount sorbed $\left(\mu \mathrm{g} \mathrm{g} \mathrm{g}^{-1}\right), \mathrm{b}$ is the maximum $\mathrm{Hg}$ (II) ions uptake per unit mass of soil $\left(\mu \mathrm{g} \mathrm{g}^{-1}\right)$ related to adsorption capacity. In short, $\mathrm{K}$ reflects the retention intensity and the number of available sites for a sorbate. Fig. 5, presents the linearized form of Langmuir model after the experimental data was fitted. The values of $\mathrm{b}$ and $\mathrm{K}$ were evaluated from the slope and intercept respectively for the seven isothermal lines and presented in Table 5 .

The Langmuir adsorption capacity for the seven Ankobra Basin soils for $\mathrm{Hg}$ ranged from $1.60 \mathrm{~L}$ $\mathrm{kg}^{-1}$ to $12.16 \mathrm{~L} \mathrm{~kg}^{-1}$ (Table 5). The Langmuir Energy for these soils for $\mathrm{Hg}$ ranged from 0.012 to 0.510 . The Langmuir energy reflects the retention intensity and the number of sites available for a sorbate. With regards to soil properties, negative correlation was found to exist between the Langmuir adsorption energy and soil $\mathrm{pH}(\mathrm{r}=-0.58, \mathrm{p}<0.05)$, and correlation between Langmuir adsorption energy and organic matter was insignificant $(r=-0.19, \mathrm{p}<$ 0.05) (Table 6).

The Freundlich model is a case for heterogen- 
Table 4: Correlation coefficient for relationship between distribution coefficient and some soil characteristics

\begin{tabular}{lcccc}
\hline & $(\boldsymbol{\%})$ Clay & OM & $\mathbf{p H}$ & $\mathbf{L o g ~ K}_{\mathbf{d}}$ \\
\hline Clay (\%) & & 0.26 & 0.48 & 0.65 \\
OM & 0.26 & & -0.11 & 0.35 \\
$\mathrm{pH}$ & 0.48 & -0.11 & & -0.17 \\
$\log \mathrm{K}_{\mathrm{d}}$ & 0.65 & 0.35 & -0.17 & \\
\hline
\end{tabular}

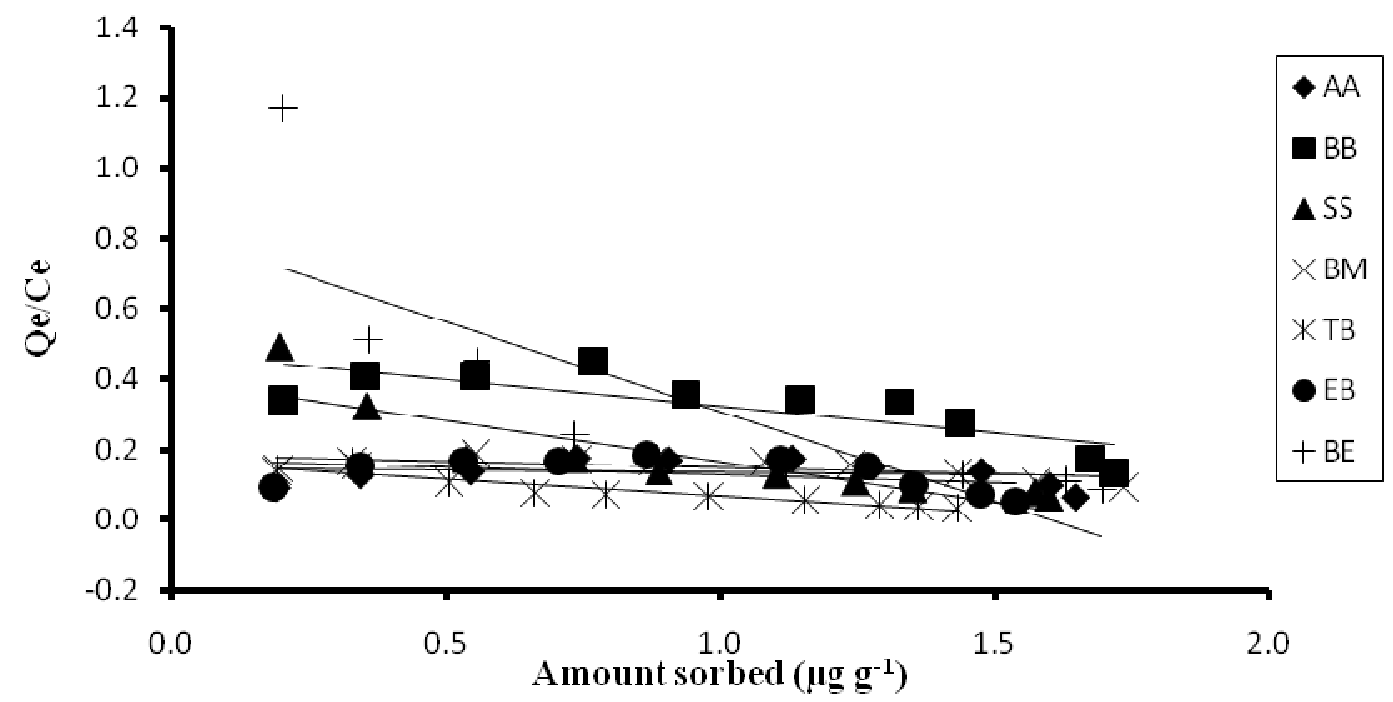

Fig. 5: Langmuir model for Ankobra basin soils

Table 5: Parameters for the Langmuir equation

\begin{tabular}{ccccc}
\hline Sample code & Equation & b & K & $\mathbf{R}^{2}$ \\
\hline AA & $\mathrm{y}=-0.012 \mathrm{x}+0.146$ & 12.16 & 0.012 & 0.03 \\
BB & $\mathrm{y}=-0.149 \mathrm{x}+0.472$ & 3.16 & 0.149 & 0.63 \\
SS & $\mathrm{y}=-0.232 \mathrm{x}+0.397$ & 1.71 & 0.232 & 0.75 \\
BM & $\mathrm{y}=-0.036 \mathrm{x}+0.184$ & 5.11 & 0.036 & 0.41 \\
BE & $\mathrm{y}=-0.510 \mathrm{x}+0.817$ & 1.60 & 0.510 & 0.64 \\
TB & $\mathrm{y}=-0.098 \mathrm{x}+0.166$ & 1.69 & 0.098 & 0.88 \\
EB & $\mathrm{y}=-0.044 \mathrm{x}+0.172$ & 3.91 & 0.044 & 0.19 \\
\hline
\end{tabular}

Journal of Science and Technology @ KNUST December 2013 
Sorption of inorganic mercury on soils from Ankobra basin... 11

eous surface energies and it gives an exponential distribution of active sites. This form of the equation was used to relate the amount of inorganic $\mathrm{Hg}$ sorbed on soil. The linear form of this model is represented by:

$\log \mathrm{Q}_{\mathrm{e}}=\log a+n \log \mathrm{C}_{\mathrm{e}}$

Where $C_{e}$ is the equilibrium concentration and $\mathrm{Q}_{\mathrm{e}}$ is the amount sorbed $\left(\mu \mathrm{g} \mathrm{g}^{-1}\right)$. The Freundlich constants $a$ and $n$, which respectively indicate the adsorption capacity and the adsorption intensity, were calculated from the intercept and slope of plot of $\log \mathrm{Q}_{\mathrm{e}}$ versus $\log$ $\mathrm{C}_{\mathrm{e}}$ as presented in Fig. 6. The parameters are presented in Table 7.

The Freundlich binding capacities for the 7 Ankobra Basin soils for $\mathrm{Hg}$ ranged from 0.175 to 0.45 . The Freundlich adsorption intensity ranged from 0.455 to 0.833 . With regards to soil properties, a slight positive correlation was found to exist between the linear distribution coefficient and $\%$ clay $(r=0.49, \mathrm{p}<0.05)$, and a strong positive correlation between Freundlich adsorption intensity and organic

Table 6: Correlation coefficients for relationship between Langmuir parameters and some soil characteristics

\begin{tabular}{lccccc}
\hline & Clay (\%) & OM & pH & b & K \\
\hline Clay (\%) & & 0.26 & 0.48 & -0.11 & -0.08 \\
OM & 0.26 & & -0.11 & 0.03 & -0.19 \\
pH & 0.48 & -0.11 & & 0.18 & -0.58 \\
b & -0.11 & 0.03 & 0.18 & & -0.56 \\
K & -0.08 & -0.19 & -0.58 & -0.56 & \\
\hline
\end{tabular}

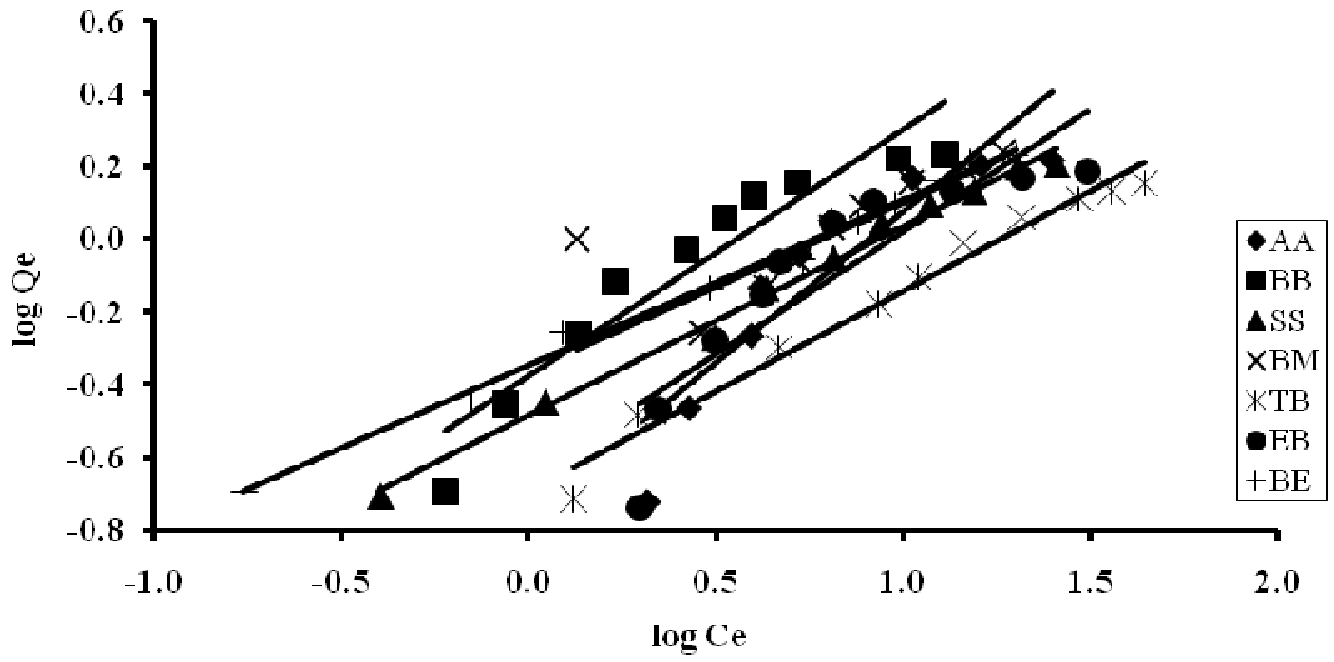

Fig. 6: Freundlich model for Ankobra basin soils 
Table 7: Parameters for the Freundlich equation

\begin{tabular}{lllll}
\hline Sample Code & Equation & $\mathbf{a}$ & $\mathbf{n}$ & $\mathbf{R}^{2}$ \\
\hline Ankobra (AA) & $\mathrm{y}=0.8329 \mathrm{x}-0.758$ & 0.175 & 0.833 & 0.37 \\
Bonsa (BB) & $\mathrm{y}=0.6747 \mathrm{x}-0.3749$ & 0.422 & 0.675 & 0.90 \\
Subri (SS) & $\mathrm{y}=0.5196 \mathrm{x}-0.4849$ & 0.327 & 0.511 & 0.99 \\
Beppoh (BM) & $\mathrm{y}=0.4611 \mathrm{x}-0.3623$ & 0.434 & 0.461 & 0.58 \\
Bawdie (BE) & $\mathrm{y}=0.6705 \mathrm{x}-0.6498$ & 0.224 & 0.671 & 0.78 \\
Teberebie (TB) & $\mathrm{y}=0.5483 \mathrm{x}-0.6919$ & 0.203 & 0.548 & 0.98 \\
Efuanta (EB) & $\mathrm{y}=0.04552 \mathrm{x}-0.3473$ & 0.450 & 0.455 & 0.99 \\
\hline
\end{tabular}

Table 8: Correlation coefficients for relationship between Freundlich constant and some soil characteristics

\begin{tabular}{llllll}
\hline & $(\boldsymbol{\%})$ Clay & OM & pH & $\mathbf{a}$ & $\mathbf{n}$ \\
\hline (\%) Clay & & 0.26 & 0.48 & 0.49 & -0.11 \\
OM & 0.26 & & -0.11 & -0.29 & 0.69 \\
pH & 0.48 & -0.11 & & -0.17 & -0.16 \\
a & 0.49 & -0.29 & -0.17 & & -0.63 \\
n & -0.11 & 0.69 & -0.16 & -0.63 & \\
\hline
\end{tabular}

matter $(\mathrm{r}=0.69, \mathrm{p}<0.05)$. There was weak negative correlation between the Freundlich binding capacities and soil $\mathrm{pH}(\mathrm{r}=-0.17, \mathrm{p}<$ $0.05)$. Similarly, weak negative correlation was found to exist between Freundlich binding capacities and organic matter $(r=-0.29, \mathrm{p}<0.05)$ (Table 8).

The goodness of fit of an experimental data is measured by the coefficients of determination $\left(\mathrm{R}^{2}\right)$ (Zaid-Ahmed and Mohammed, 2008). The $\mathrm{R}^{2}$ for the isotherms studied, has been presented in Table 9. Considering the $\mathrm{R}^{2}$ of this study, it could be deduced that, the Freundlich model showed a better fit followed by Lang- muir model and then linear. Miretzky et al. (2005) also deduced that, the Freundlich model showed a better fit than Langmuir model. This could be due to similarities in soil characteristics. The superiority of Freundlich model over the other models could be attributed to the heterogeneous surface energies and exponential distribution of active sites which are characteristics of soils. The affinity constant between the compound and the organic carbon is often well correlated to any partition coefficient by a logarithmic relationship. In a Freundlich adsorption isotherm system, the value of $\mathrm{n}$ is determined experimentally from the slope of the line which is equal to $1 / \mathrm{n}$. 
Sorption of inorganic mercury on soils from Ankobra basin... 13

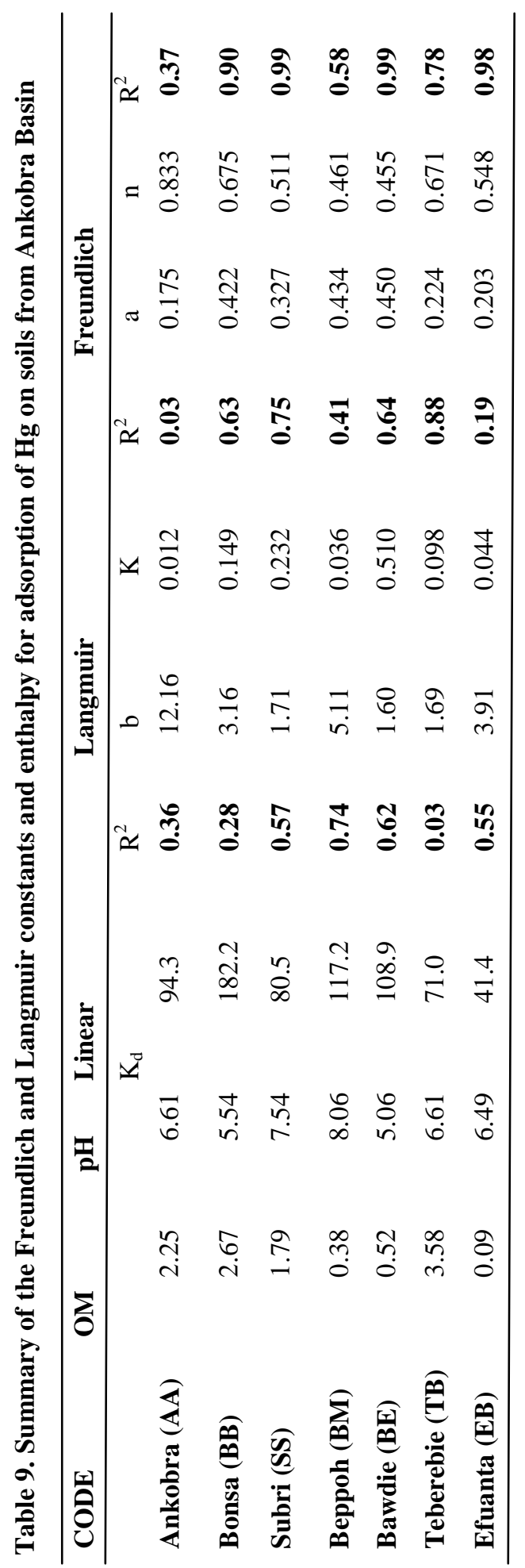

According to Ansari et al. (2009) adsorbents with $\mathrm{n}$ values near 1.0 are valid for many organic contaminants while lower values (0.4$0.6)$ are valid for heavy metals and phosphorus. All the soils had an exponent (n) lower than one, indicating that these soils could be good sorbents for Hg (II).

From the analysis carried out, the following conclusions are deduced. The THg of the soils ranged from $0.051 \mu \mathrm{g} \mathrm{g}^{-1}$ to $0.366 \mu \mathrm{g} \mathrm{g}^{-1}$ with an average of $0.15 \mu \mathrm{g} \mathrm{g}^{-1}$. The total $\mathrm{Hg}$ content measured in this study for all the soils was below the level set by US EPA $\left(200 \mu \mathrm{g} \mathrm{g}^{-1}\right)$. This study showed that a period of $90 \mathrm{~min}$ is sufficient to attain equilibrium between $\mathrm{Hg}$ (II) solution and soil. All soils had an L - type isotherm according to the classification of Giles et al. (1974) and the distribution coefficient $\left(\mathrm{K}_{\mathrm{d}}\right)$ ranged from $41.4 \mu \mathrm{g} \mathrm{g}^{-1}$ to $182.2 \mu \mathrm{g} \mathrm{g}^{-1}$. In this study, the Freundlich model showed a better fit followed by the Langmuir model and the Linear. All the soils had adsorption intensity (n) lower than one, indicating that the soils could be good sorbent for $\mathrm{Hg}$ (II).

\section{REFERENCES}

Akagi, H. and Nishimura, H. (1991). Speciation of mercury in the environment. In: Suzuki, T., Imura, N. and Clarkson, T. W. (Eds), $A d$ vances in Mercury Toxicology, Plenum Press, USA. $53-76$.

Anderson, P. R. and Christensen, T. H. (1988). Distribution coefficients of $\mathrm{Cd}, \mathrm{Co}, \mathrm{Ni}$, and $\mathrm{Zn}$ in soils. Journal of Soil Science, 39: 1522.

Ansari, R., Zanjanchi, M. A., Mohammadkhah, A. and Mosayebzadeh, Z. (2009). Removal of basic dyes from textile wastewaters using sawdust, $7^{\text {th }}$ National Conf Textile Eng, Rasht, Iran.

Biester, H., Muller, G. and Scholer, H. F (2002). Distribution and retention of mercury in three different soils contaminated by mercury in three different soils contaminated by 


\section{Azanu and Voegborlo}

mercury emissions from chlor-alkali plants. Science of the Total Environment, 284:177189.

Estes, G. O., Knoop, W. K. and Houghton, F. D. (1973). Soil-plant response to surfaceapplied mercury. Journal of Environmental Quality, 2: 451-452

Fang, S. C. (1978). Sorption and transformation of mercury vapour by dry soil. Environmental Science Technology, 12: 285-288.

Fitzgerald, W. F., Engstrom, D. R., Mason R. P. and Nater, E. A. (1998). The case for atmospheric mercury contamination in remote areas, Environmental Science Technology, 32: $1-7$.

FAO (Food and Agriculture Organization of the USA) (2006).World reference base for soil resources (World Soil Resources Report 103).

Gee, G.W. and Bauder, J.W. (1986). Particlesize analysis. In: Klute, A. (Eds), Methods of soil analysis, Part 1. Physical and mineralogical methods.ASA, Madison, Wisconsin. 377382.

Giles, C. H., Smith, D. and Huitson, A. (1974). A general treatment and classification of the solute adsorption isotherm (Theoretical). Journal of Colloid and Interface Science, 47: 755-765.

Grigal, D. (2003). Mercury sequestration in forests and peat lands: A review. Journal Environmental Quality, 32: 393 - 405.

Harter, R. D. (1991). Kinetic of sorption/ desorption processes in soil. In: Sparks, D. L. and Suarez, D. L. (Eds), Environmental soil chemistry, Soil Sci. Soc. Amer. Pub. Madison, WI. 135-149.

Hilson, G. (2001). A Contextual Review of the Ghanaian Small-scale Mining Industry,
Mining, minerals and sustainable Development, 76: 1- 29.

Jackson, T. A. (1997). Long-range atmospheric transport of mercury to ecosystems, and the importance of anthropogenic emissions - A critical review and evaluation of published evidence. Environmental Revision, 5: 99 120.

Khalid, R. A., Gambrell, R. P. and Patrick Jr., W. H. (1977). Sorption and Release of Mercury by Mississippi River Sediment as Affected by $\mathrm{pH}$ and Redox Potential, In $\mathrm{H}$. Drucker and R. E. Wildung (Eds.), Biological Implications of Metals in the Environment, Proceedings of the 15th Annual Hanford Life Science Symposium, Richland, Washington. 297-314.

Kortatsi, B. K. (2004). 'Hydrochemistry of groundwater in the mining area of TarkwaPrestea, Ghana', $\mathrm{PhD}$ thesis, University of Ghana, Legon-Accra, Ghana.

Lag, J. and Steinnes, E. (1978). Introduction on the mercury cycle and its implications on human health and the environment. Acta Agriculturae Scandinavica, 28: 393.

Lamar, W. L. (1968). Evaluations of Organic Colour and Iron in Natural Surface Waters, In: Pap, P. (Ed.). Geol. Surv. U.S. Govt. Printing Office, Washington, D.C., 24-29.

Landa, E. R. (1978). The retention of metallic mercury vapor by soils. Geochimica et Cosmochimica Acta, 42: 1407-1411.

Mason, R. P. and Sullivan, K. A. (1997). Mercury in Lake Michigan. Environmental Science Technology, 31: $942-947$.

McLean, E. O. (1982). Soil pH and Lime Requirement. In: Miller R. H. and Keeney, D. R. (Eds). Methods of Soil Analysis, Part 2. Second edition, ASA and SSSA, New York, USA, 199-224 
Sorption of inorganic mercury on soils from Ankobra basin... 15

Melamed, R. and Villas-Boas, R. C. (1998). Phosphate-background electrolyte interaction affecting the transport of mercury through a Brazilian Oxisol. Science of the Total Environmental, 213: 151-156.

Miretzky, P., Bisinoti, M. C., Rocha, J. C. and Jardim, W. F. (2005).Factors affecting $\mathrm{Hg}$ (II) adsorption in soils from the Rio Negro basin (Amazon). Quimica Nova, 28: 438443.

Nelson, D. W. and Sommers, L. E. (1975).A rapid and accurate method for estimating organic carbon in soil. Proceedings of the Indiana Academy of Science, 84: 456 - 462.

Parkpian, P., Thongra-ar, W., Delaune, R. D. and Jugsujinda, A. (2001). Adsorption and desorption of mercury by Bangpakong River sediments as influenced by salinities. Journal of Environmental Science and Health, 36: 623-640.

Schlüter, K. and Gäth, S. (1997). Modelling leaching of inorganic $\mathrm{Hg}$ (II) in a Scandinavian iron - humus podzol - validation and long - term leaching under various deposition rates Water, Air, and Soil Pollution, 96: 301-320.

Schnoor, J. (1996). Environmental modelling. Fate and Transport of Pollutants. Water, Air and Soil, J. Wiley and Sons. Inc.: New York. 682.

Schroeder, W. H. and Munthe, J. (1998). Atm- ospheric mercury - An overview. Atmospheric Environment, 32: 809-822.

Semu, E. and Singh, B. R. (1987). Adsorption of mercury compounds by tropical soils: II. Effect of soil: solution ratio, ionic strength, $\mathrm{pH}$ and organic matter. Water, Air and Soil Pollution, 32: 1-10.

Trost, P. B. and Bisque, R. E. (1972). Distribution of Mercury in Residual Soils, In: Hartung, R. and Dinman, B. D. (Eds.), Environmental Mercury contamination, Ann Arbor Science Publishers, Ann Arbor, Mich., 178196.

Yin, Y., Allen, H. E., Li, Y., Huang, C. P. and Sanders, P. (1996). Adsorption of mercury (II) by soil: Effects of $\mathrm{pH}$, chloride and organic matter. Journal Environmental Quality 25: $837-844$.

Yin, Y., Allen, H. E. and Huang, C. P. (1997a). Kinetics of mercury (II) adsorption and desorption on soil. Environmental Science Technology, 31: 496 - 503.

Yin, Y., Allen, H.E., Huang, C. P. and Sanders, P. (1997b). Adsorption/desorption isotherms of Hg (II) by soil, Soil Science, 162: 35 - 45.

Zaid - Ahmed, A. and Mohammed, A. S. A. (2008). Thermodynamics and Kinetics Studies of Iron (III) Adsorption by Olive Cake in a Batch System. Journal of the Mexican Chemical Society, 52: 108 -115. 